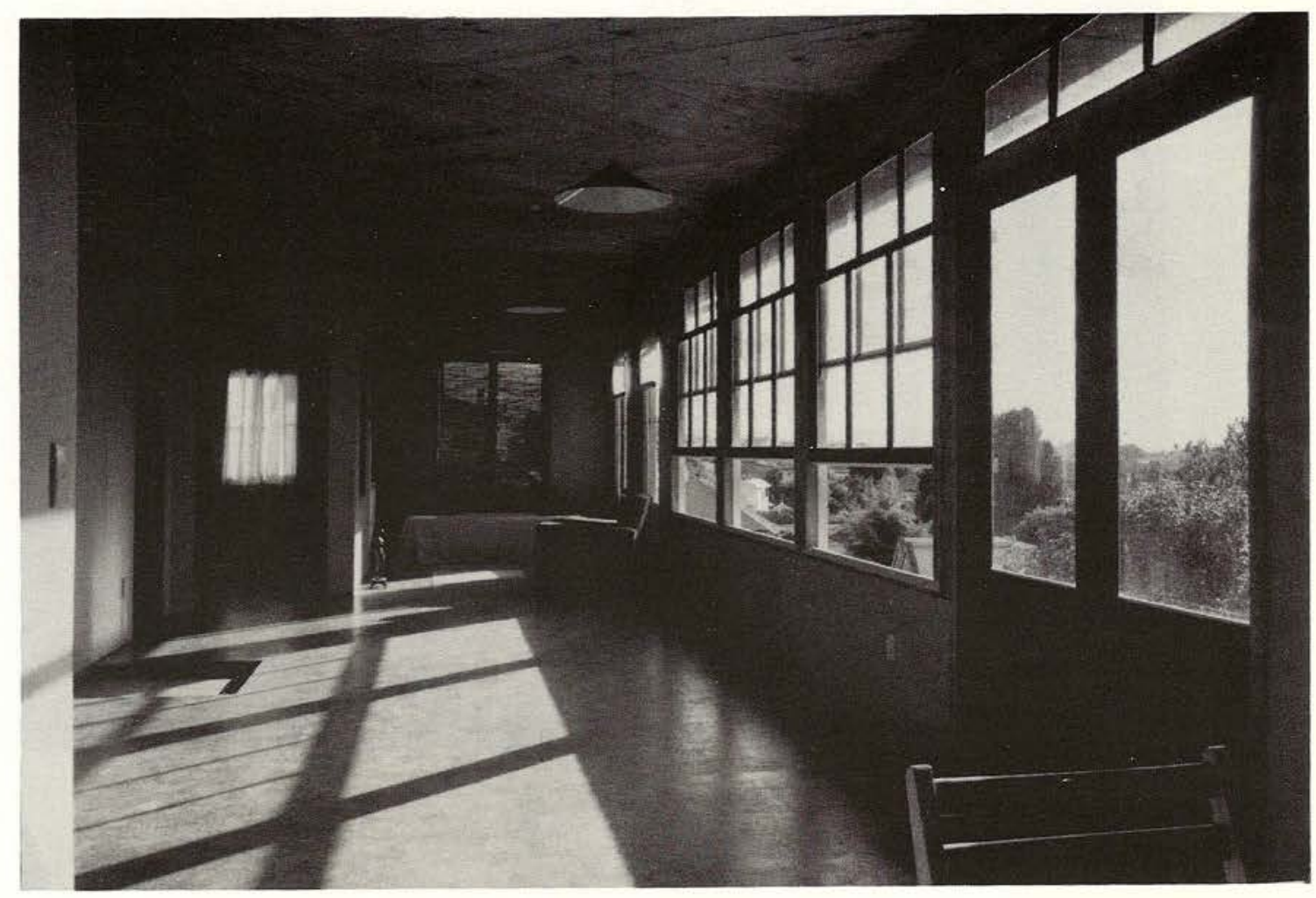

Kirkland House: Sofa

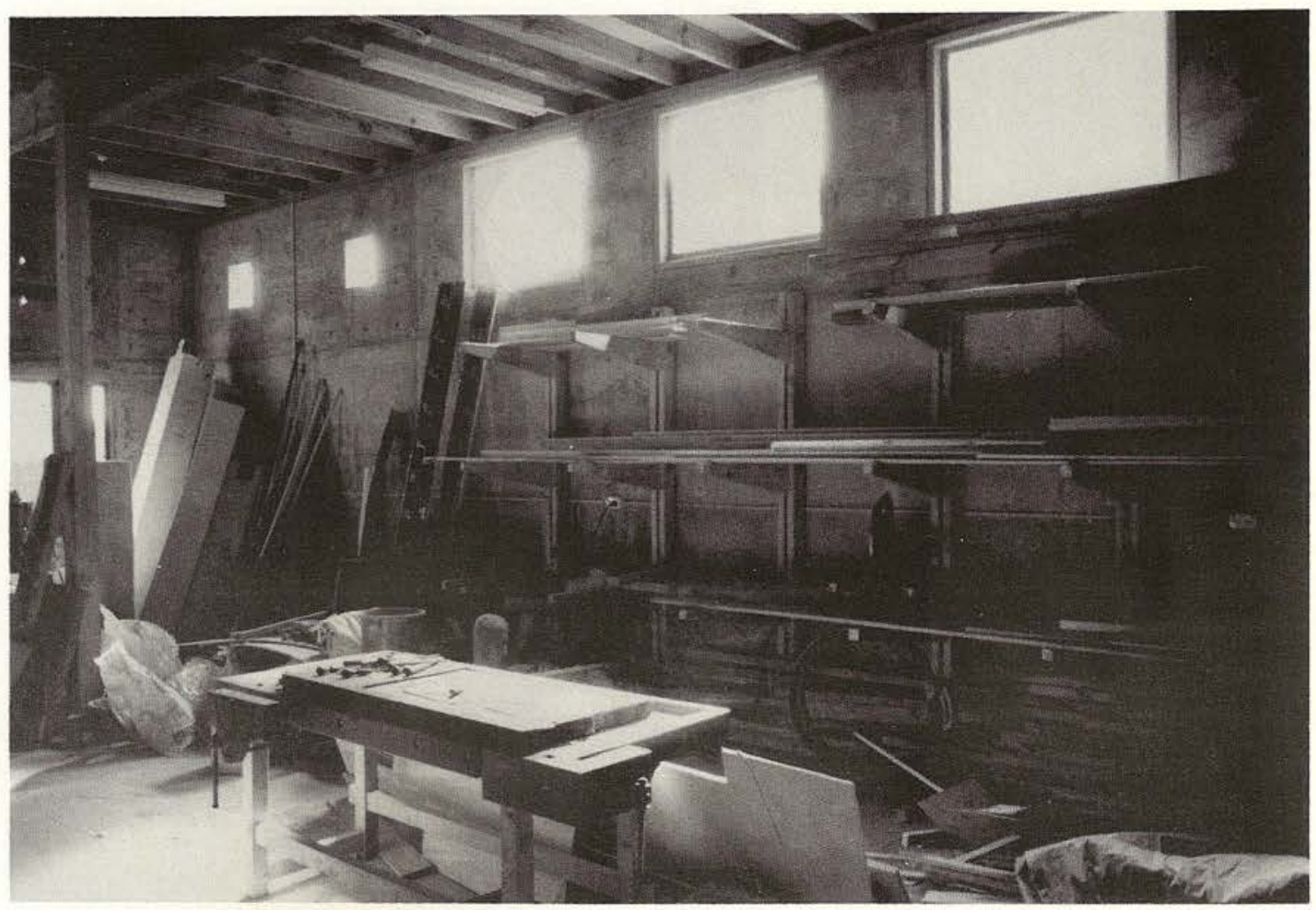

Kirkland House: Work Shop in basement 


\section{The Kirkland House and the Sinclair and Shouler House}

John D Dickson

The site disposition of these two houses seems to have less to do with nostalgia for the nineteenth-century urban residential-streetscape, than with confident placement upon upthrust-landform, and with full spatial participation in the surrounding landscape and skyscape.

\section{THE SINCLAIR AND SHOULER HOUSE}

The tall, narrow west-end facade of the Sinclair and Shouler House, dramatised by first-floor entry, has a theatrical air. A sense of dislocation of a town-house facade, combined with the accoutrements of more spacious environs, notably a palm-tree and open-light, give the sense that even in one's approach one is actually stationary and it is the world that is moving, to any locale, to any height. One is dazzled by this display of the world's virtuosity, and by the apparent weightlessness of material such as a brass door-knocker, which in a London town-house context would be redolent of solidity and permanence, these excited by its polished glint, but here it is flashing through high-trapeze-space caught up in a Zabriskie Point tour en l'air. Sinclair is clearly less interested in what things are than in what these might become, and to enter this house is to be caught up in such a transformation. Reassurances of New Zealand's staid building - concrete-block, timber, plywood, corrugated-iron - here have a trompe-1'oeil quality, with building elements balanced and counter-balanced in acrobatic display. One senses that space beyond the door is of another kind. Meanwhile one is observed by the display itself, for bemusedly levitating two floors above is a window-seat with swan-necked rafters.

Through the door is indeed another world, a rectangular hall the length and width of the house it seems, with a central line of posts. Is module here too intrusive? But surely less so than in the work of New Zealand's modern rationalists such as the Group Architects. The hall spills to ground-level at its east-end with rhythmic alternation of vertical windows and wall on the north-side. A lean-to serves to the south butting into the ridge. Here is one large room yet does one sense from the module, partitions and corridors stacked away? Under the stairs perhaps? A light 


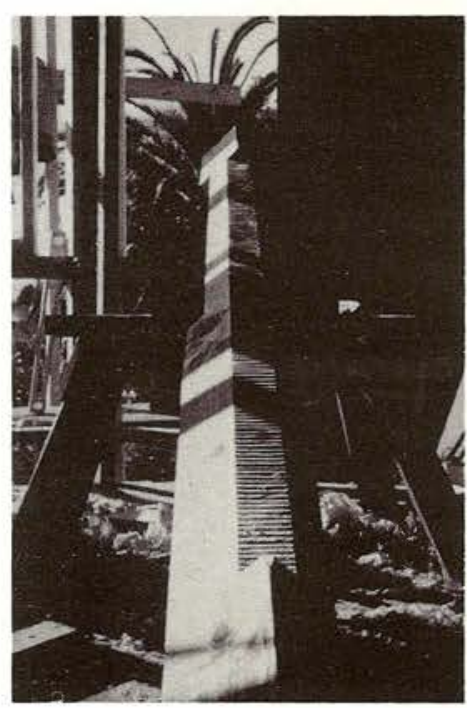

touch of classical intention composes this room twinned beneath at ground-level. A hall in plan but not in height. On this floor one again senses movement all around, yet there is nowhere to go, except into a cupboard under the stair wherein access to the lower-floor is found. Curiously confined as on a boat, one can pace length, and there are lateral encounters with posts. And as if boats are moored alongside each other, rhythmic intimation of buildings nearby direct one's attention back into the room, where movement is stylised ingeniously, as in the lean-to kitchen where all its appurtenances seem to be contained in bins-on-wheels or dramatically, as by the stair crafted by Neil Kirkland, which descends from above like a thunder-bolt from Zeus, or perhaps it is the lighter flash of Mercury's tripping. Despite these disturbances the room undoubtedly alludes in plan to Sinclair's admiration for monastic and vernacular buildings in the South of France and to later chateaux. One senses this in details such as the proportion and placement of windows, and in the room's simple outline and construction, but without the appearance of stone. Is there here also, nostalgia for history's inter-tidal zone? For the library of Bishop Selwyn at Parnell? Or for that by Lippincott at the University of Auckland, where recently, partitions and corridors have been re-deployed? Life in this room is meanwhile luxurious whatever the incoming-tide may bring.

This first-floor room is centered on its south-wall, on a side-board painted Mediterranean blue-green, from which, colour accents spring out into the room; lemon, orange perhaps, or blue ceramic. Whatever momentary still-life is here, each frame gives way to colour dynamics in the larger space of the room and inevitably toward red. One is aware that everything including the floor is painted, as if an old building has been converted with pipes and wires cut through its joists. The room recycles itself endlessly; cycles of matt and gloss texture construct a succession of trompe-l'oeil scenarios in the large back-reaching room-space. Sinclair's command of spatial-openness places him as the twentieth-century's child sprung from the French ethos of fin de siècle painters such as Matisse, and with the colour-sense and brightness of Le Corbusier's painted kouros, and accustomed to the liveliness of a ballet-set by Picasso brilliantly renewed by David Hockney. Yet maybe, as one glances at the Minoan-columned table, is there not a touch of necropolis in this realm of super-colour so evocative for Ancient People of eternity's paradise?

If we have accounted for the lightness and agility of Sinclair's cyclist temperament; and we shall take as an axiom of Sinclair's design that architecture expresses the person; this room in its polychromy suggests also a neo-classical bravura, a touch of gravity and composure, expressive of Kirsten Shouler's Danish heritage perhaps; an insistence on design and form in everything; a Scandinavian recognition of beauty; and an irresistible attraction to the Southern-world of colour and warmth. An alliance of architecture in New Zealand with a nineteenth-century neo-classical world effected in timber, is re-stated here. Yet in this room in which joie de vivre through colour dominates, we are seemingly untroubled by Scandinavian 


\section{THE KIRKLAND HOUSE}

On approaching the Kirkland House one encounters at its south-west-end, a concrete basement-workshop, over-sailed by a slight cantilever of the timbered living-quarters above. Enclosed by concrete of precise and smooth surface-finish, and with half its volume lodged in the earth of the sloping site, the basement makes an emphatic statement of solidity. A steel-beam and posts, supporting lofty joists, together with the concrete walls and floor, define a volume impressive in a domestic milieu. Here, the place is fixed, whatever comes in or goes out. This scale is qualified on the south-west facade by the only low-window, and at the sub-terranean northeast-end, a mezzanine-alcove cut into the earth, provides a drawing-office above the heavy-work ground-level. In recalling Antonello da Messina's painting of Saint Jerome in his study, one nervously searches for Saint Jerome's lion. Light floods down into the workshop from high, separately defined windows, some qualified with degrees of translucency. This is a cavernous in-world; an artisan's work and storage-space up front, proudly manifest, yet capable of privacy and seclusion. Somewhere within there is an inter-connecting stair, but this is played down. There is no discernible applied finish to the architectural elements of concrete, wood, and steel.

The concrete walls of the basement are qualified and geometrically organised by means of bands of red aggregate incised with under-cut shadow, and with friezerondels and a cavetto-cornice, and green-plugged tie-holes in regular patterns. Thus the walls, in accounting for hydrostatic pressure and successive pours, make reference also to mud-brick coursing and masonry, to Egyptian and Syrian ablaq patterns, and to geological processes of sedimentation. This is not rough concretework anticipating concealment, but construction of quality. Kirkland is clearly interested in finding out what can be achieved, and what he with his own hands can do. There is water here, outside at the door, and fire - a forge and anvil - one pace within, beneath where springs above a corbelled, arcuated, qualification of the concrete-wall at first floor level, derived bluntly from circles in a robust Roman manner. But this basement-workshop, open to the south-west, seems a cold place, at least in winter, and contrasts with the sun-dried timber-world above.

Intimation of the north-west orientation of the first-floor is discernible on the south-west facade, where the symmetries are complex. A pair of parallel windows, set in slightly protruding, plastered timber-work, express enclosure and confirm a closed south-east flank to the house; whereas to the north-west, timber weatherboards and plywood, framed by timber pilasters, plinth, and architrave, together with a broader eave indicate a loggia, the full extent of which occupies the entire north-west facade. The whole length of the house is thus framed rhythmically by pilasters, architrave, and plinth, in the manner of the Palazzo della Cancelleria at Rome. This long glazed-loggia is qualified at its ends by timber containment. On 
account of its colour and textural differentiations, this wall has the subtlety and impact of a painting. Apprehending this at close-quarters, on rounding the corner from the south-west, and then raised-up gradually by a stair to become level with the centre of this painting toward the north-east-end, one at the moment of penetration becomes Archangel to the loggia within. Yet, although one discerns centrality and module with bays defining a rhythm closed by each end, the length of the composition is sufficient to turn one's mind from Fra Angelico's Annunciation, to Duccio's gold Majestas with its serried ranks of figures to each side. By this flight of fancy I mean to convey that there is a breath-taking majesty, to the discerning eye, on entering this house; in experiencing the composition of this painterly facade with its sky-blue doors, red-gold boards, cream joinery, and below this world of blue and gold, the earth-realm of red, grey, and green. If at this moment, one was to step back into the landscape void, and view the house from a distance as one might have done on approaching the place, the siting and prominence of the form and shadows of eave and windows, would clearly reveal the loggia, held from behind by the solid, plastered walled-enclosure. But close-to one's attention is held by the glint and absorption of surface, by the fine, lineardetailing of joinery and mouldings and incised relief, with its black crevices of shadow, and by other concavities of glowing shade.

Stepping inside, under the hipped-roof of the house, is a moment to savour. A long room the entire length of the house, and independent of its immediate environs at ground-level, except at its north-east-end, is orientated toward the landscape, but not frontally, for this direction is brutally blocked by the neighbouring house to the north. Instead one sweeps out into the landscape progressively, along the depth of the room; a direction reinforced by oblique walls and doorways. There is a sense of belonging, and in-dwelling of the landscape through a linked succession of especially broad double-hung windows with fine glazing-bars, all of which when raised together, open the central, wider space, entirely. The room is as much an Elizabethan gallery as it is a New Zealand verandah. Its chevroned and battened timber-boarded ceiling, zigzagging along its entire length, makes the hieroglyph for water, and thus suggests a water-space below reflecting up into the room. There is also, in this pattern and texture, annunciation of Archangel wings, a beneficent outline above, as from the fronds of the palms outside the windows. The room is slightly contained and separated at each end. All the spaces of the house on this floor open onto this long gallery, and two of these at either end of the house, are conceived of as square rooms oversailing the concrete basement below. These are closed to the south-east, provided with cupboards, bound internally with mouldings, and open through shuttered windows onto the long gallery, as well as opening directly to the morning or evening through inward-opening shuttered windows. Symmetrical, self-contained, refined further in their linings and mouldings, these rooms celebrate the intimacies and value of human shelter; one room for necessity, and another for the other - whatever that might prove to be; 


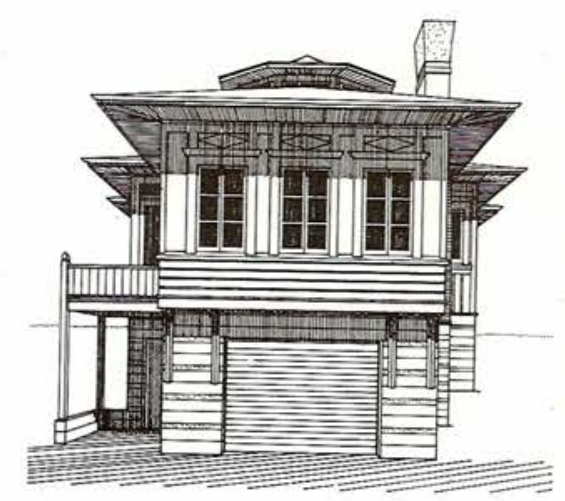

Mc Kenzie House(1990)

Perspective view from North

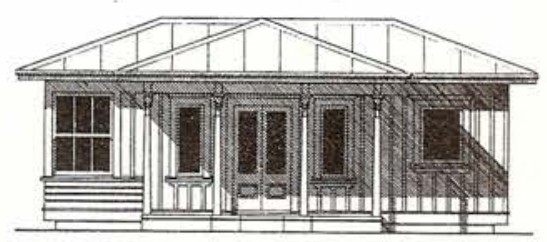

Maxwell House (1986)

Nor-west elevation the night, visitors, or whatever one chooses, or whatever may be forced upon the household.

It is obvious that considerable thought has been given to sun-protection and sunpenetration, to ventilation and insulation, to site orientation, and to the complementary roles of room and gallery; to a simple gradation of inside, inbetween, and outside. All these considerations have been reconciled with a classical approach to form and to use of a New Zealand vernacular. Furthermore, recognition has been made of the similarity between the New Zealand vernacular and the Ottoman vernacular. The Kirkland House, in its planning and construction, expresses curiosity about this similarity. Both the New Zealand and Ottoman vernaculars are committed to the external landscape, to a degree of open-living in close association with others; both have been developed in temperate-zones using a wood and masonry based technology; both are based on Mediterranean culture; and both respond to European custom. The semblance of the Kirkland House to Ottoman house-types, is not mere reference ethnically, or architecturally, nor is it simply coincidental as part of a wider affinity with a classical approach, but it is rather, an intended invigorating implant, implying that the New Zealand vernacular can be even more richly aligned to an appreciation of material, technology, and form. This seems to be a reasoned emotional choice. Crossfertilisation and the vigour of hybridisation is the goal. Yet there can be doubts. There is perhaps a fine line between this path Kirkland is treading and romanticism. Can this house be clearly seen as the outcome of one or the other? Its form is clear enough, with its sofa (hall), and two sekiliks (raised seating alcoves) at either end, and two oda (rooms) opening onto the sofa. More allusive tendencies are already embodied in New Zealand's Victorian, and Orientalist-orientated Arts and Crafts traditions, and their development in the context of the bungalows of the $1920 \mathrm{~s}$ and 1930s. The Kirkland House is too frank in its use of Ottoman form to be considered in these terms. Its curiosity about Ottoman architecture is too far-reaching; its reorganisation of the New Zealand vernacular is too deep, too convincing, too classically enacted to be solely a romantic interest. But is this nevertheless a direction backwards?

The Kirkland House, by means of its detailed finesse and quality, and consideration of environmental performance, indicates the considerable distance this designdirection has already been advanced. A review of Kirkland's earlier design and building-work is beyond the scope of this review. Suffice to note an assessment of the Modern-Movement and its Ottoman susceptibility in the exquisite loggia for Sir Alan and Lady Stewart, (1982) on the north and west-front of their cliff-top house at Whakatane; also the carved Radiata posts in the Chisholm House, (1985) at Maxwell Avenue, Grey Lynn; and the Maxwell House, (1986) at Army Bay, Whangaparaoa. The Maxwell House has a cruciform hipped-roof of singular beauty with a central sofa, glazed on its east-arm, and a porch with carved posts on its north-arm. The 
implications of this form for weather-boarding, timber-framing, concrete-work, corrugated-iron, and double-hung sashes are all convincingly essayed. In the recently designed McKenzie House (1990) at Paekakariki, classical elements are further closely adapted to a New Zealand life-style. Its symmetries and regularities are balanced by the peculiarities of its situation. But of course that is exactly what the Ottoman tradition, and any classical vernacular, is practised at. This house is satisfyingly sited according to a New Zealander's expectation, no matter how much one equates the Bosphorus with Cook Strait; up a hillside, overlooking the sea, managing with its neighbours to maintain its own advantage of identity and exhilaration; with a basic variety of internal spaces, and deploying New Zealand vernacular elements in specific ways; with also a touch of Middle New Zealand déjà-vu.

In conclusion, whatever the independent failings, or thoughtful detail, of these two Haslett Street houses, they can be seen to share something of distinction which closely identifies them with their own neighbourhood. I think it is their siting, their larger response to the landscape, and their use of a familiar building-vernacular, which fastens these two houses securely in place and which gives them local identity. This is not distracted from by arbitrary style, but rather, their sense of enlivened ordinariness might well cause the viewer to become aligned sympathetically with them. 